\title{
Danger on the rise: diurnal tidal state mediates an exchange of food for safety by the bar-bellied sea snake Hydrophis elegans
}

\author{
Megan R. Kerford ${ }^{1}$, Aaron J. Wirsing ${ }^{2, *}$, Michael R. Heithaus ${ }^{2}$, Lawrence M. Dill ${ }^{1}$ \\ ${ }^{1}$ Behavioural Ecology Research Group, Department of Biological Sciences, Simon Fraser University, 8888 University Drive, \\ Burnaby, British Columbia V5A 1S6, Canada \\ ${ }^{2}$ Department of Biological Sciences, Marine Biology Program, Florida International University, Biscayne Bay Campus MSB, \\ 3000 NE 151 Street, North Miami, Florida 33181, USA
}

\begin{abstract}
Prey vulnerability to predation can depend on abiotic conditions. Thus, prey individuals may adjust their investment in anti-predator defense according to changes in one or more abiotic factors. We explored this possibility in Shark Bay, Western Australia, where the bar-bellied sea snake Hydrophis elegans is under threat of predation by the tiger shark Galeocerdo cuvier, asking specifically whether the diurnal tidal state influenced snakes' selection of exposed foraging habitat (sand flat) and refuge habitat (seagrass). At high tide, when both habitats were easily accessible to sharks, $H$. elegans selected seagrass habitats, where its food is relatively scarce. At low tide, when sharks had limited access to both habitats, $H$. elegans used the 2 habitats equally but foraged exclusively over sand flats. We concluded that $H$. elegans is sensitive to the danger of tiger shark predation and trades food for the safety of a refuge when diurnal tidal conditions in its foraging habitat expose it to sharks. Our results suggest that predation risk should be considered in studies of sea snake habitat use and that important variation in predator-prey interactions may be missed if relevant abiotic conditions are ignored.
\end{abstract}

KEY WORDS: Abiotic factors · Foraging · Galeocerdo cuvier · Hydrophis elegans · Predation risk · Prey vulnerability · Tiger shark

Resale or republication not permitted without written consent of the publishe

\section{INTRODUCTION}

Prey vulnerability to predation can show marked spatial and temporal variability (Lima 1998, Lima \& Bednekoff 1999). This variation can correspond with changes in a host of abiotic conditions including diel state (e.g. Culp et al. 1991), dissolved oxygen concentration (e.g. Moore \& Townsend 1998), habitat structure (e.g. Talman et al. 2004), moonlight (e.g. Griffen et al. 2005), precipitation (e.g. Ovadia \& Schmitz 2004), salinity (e.g. Handeland et al. 1996), temperature (e.g. Weetman \& Atkinson 2002) and water depth (e.g. Gawlik 2002). In many cases, therefore, we might expect the amount of anti-predator investment by prey individuals to correlate with fluctuations in one or more abiotic factors and overall levels of investment in safety to be a function of the time that abiotic conditions render the environment dangerous (Lima \& Bednekoff 1999, Hamilton \& Heithaus 2001). Anti-predator behavior is often incommensurate with foraging, so variation in abiotic conditions that influence the need for anti-predator defense could influence exploitation rates of resources by prey species. Thus, studies of the interaction between abiotic conditions and antipredator investment should lead to an improved understanding of community dynamics.

In marine systems the influence of abiotic conditions on interactions between sessile invertebrates and their predators has long been appreciated (Sousa 1984, Warner et al. 1993). The possibility that abiotic conditions meditate interactions between more mobile marine prey species and their predators has rarely 
been explored (e.g. Heithaus \& Dill 2002, Hays 2003, Wirsing et al. 2007a), and no study to date has investigated this question using a sea snake as the model species. Accordingly, we asked whether diurnal tidal state influenced the use of exposed and refuge habitats in an Australian embayment (Shark Bay, Western Australia) by bar-bellied sea snakes Hydrophis elegans threatened with tiger shark Galeocerdo cuvier predation.

Hydrophis elegans is a large hydrophiid that occurs in coastal waters along northern Australia and southern New Guinea (Heatwole 1999). In Shark Bay, $H$. elegans has access to 2 nearshore habitats: shallow sand flats and seagrass meadows. Sand flat habitats are home to snake eels (Ophichthidae) (McCosker \& Rosenblatt 1993), on which $H$. elegans appears to specialize (Kerford 2005), but are exposed and therefore offer little protection from sharks. In contrast, seagrass meadows offer little food but feature dense vegetation that promotes crypsis (M. R. Kerford pers. obs.) and likely provides a physical refuge from sharks (Orth et al. 1984). Both habitats are used by tiger sharks, which are a major consumer of sea snakes, including $H$. elegans, in Shark Bay (Heithaus 2001, Simpfendorfer et al. 2001) and elsewhere (Simpfendorfer 1992). During low-tide periods, however, tiger sharks are rarely sighted in either habitat (M. R. Heithaus unpubl. data, M. R. Kerford pers. obs.), likely because their mobility is restricted. Consequently, $H$. elegans may only incur a predation cost when using sand flats instead of seagrass meadows at high tide. This cost may be especially high for foraging snakes, which leave their bodies vulnerable to attack while probing snake eel burrows (Kerford 2005).

We tested the hypothesis that Hydrophis elegans sacrifices food for safety when diurnal tidal conditions render its foraging habitat too risky. Under the assumptions that food (snake eel availability) is largely restricted to sand flats and that seagrass meadows act as a refuge for $H$. elegans, this hypothesis predicts that (1) relative use of seagrass meadow habitat should be greatest at high tide when the danger of predation in sand flat habitat is high and (2) foraging should occur primarily in sand flat habitats and during low tide when shark predators are virtually absent. Conversely, if $H$. elegans is insensitive to changes in tiger shark predation risk caused by tidal variation, then relative $H$. elegans abundance across the 2 habitats and forager abundance in sand flat habitat should be independent of tidal state.

\section{MATERIALS AND METHODS}

Study site. We conducted the present study between February and April 2004 in the Eastern Gulf of Shark Bay (ca. $25^{\circ} 45^{\prime} \mathrm{S}, 113^{\circ} 44^{\prime} \mathrm{E}$; Fig. 1a), which lies at the southern extent of the distribution of Hydrophis elegans (Heatwole 1999). Shark Bay is remote, lightly populated and has been protected as a World Heritage Area since 1991. Consequently, it is considered to be relatively pristine. Its $H$. elegans and tiger shark populations are large and free from anthropogenic exploitation (Heithaus 2001, Kerford 2005, Wirsing et al. 2006).

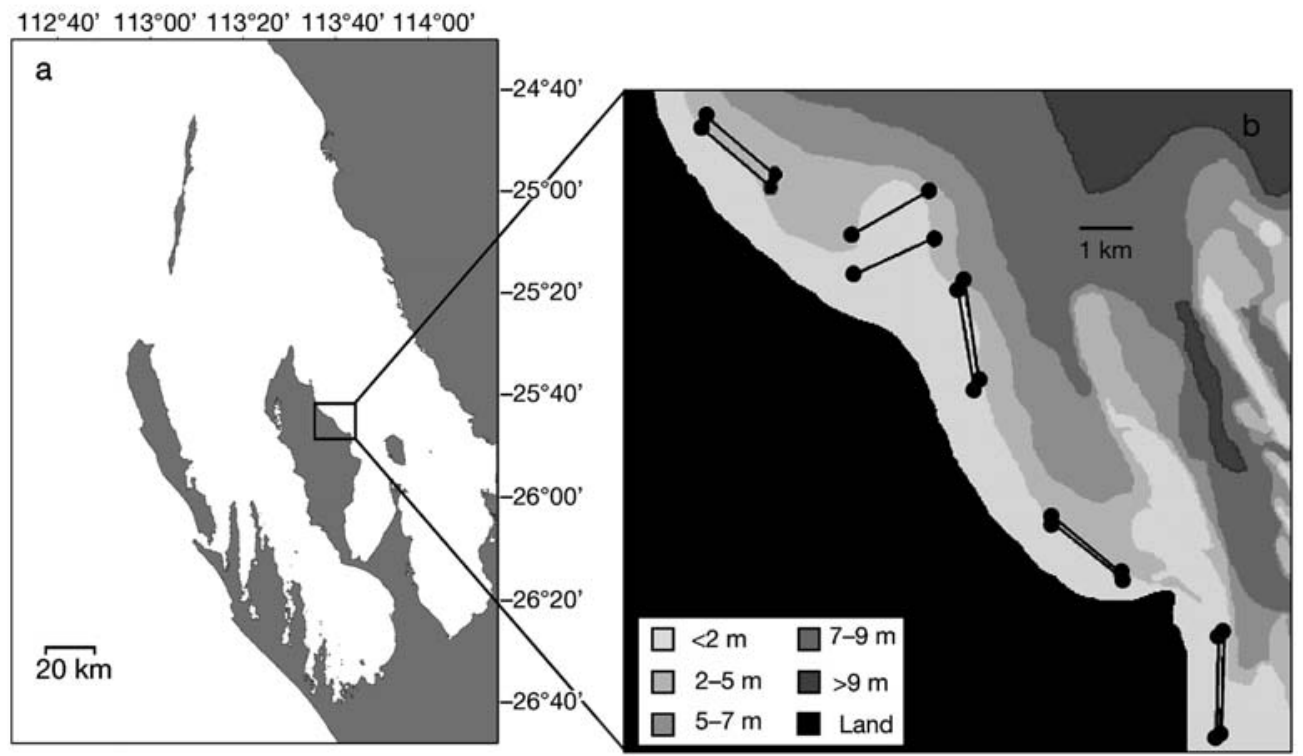

Fig. 1. The Eastern Gulf of Shark Bay, Western Australia (a) and paired transects (b) ( $\mathrm{n}=5$ pairs) established in nearshore sand flat and seagrass habitats 
Sea snake habitat use. We quantified the use of sand flat and seagrass meadow habitats by Hydrophis elegans using paired $2 \mathrm{~km}$ transects in 5 nearshore locations (Fig. 1b). At each location one transect was placed in sand flat habitat and the other in seagrass habitat. All seagrass transects bisected meadows comprising a mixture of 2 temperate seagrass species, Amphibolis antarctica and Posidonia australis, which predominate throughout much of the bay. These meadows were dense, continuous and extended to an average of $25 \mathrm{~cm}$ above the substrate (A. J. Wirsing unpubl. data), providing ample hiding possibilities and protective cover. At all locations seagrass transects were immediately offshore of sand flat transects, but depths were similar (generally $\leq 3.5 \mathrm{~m}$ ). All transect pairs were separated by at least $100 \mathrm{~m}$. Transects were surveyed by 2 observers driving a $4.5 \mathrm{~m}$ vessel at ca. $7 \mathrm{~km} \mathrm{~h}^{-1}$; no transect was visited on consecutive days, and the order of visitation on any given day was haphazard. Survey effort was allocated evenly to sand flat and seagrass meadow habitats (94 passes each). Moreover, effort was similar at high and low tide in both sand flats (47 passes each) and seagrass meadows (52 and 42 passes, respectively). Tidal state was recorded at the beginning of each transect. We considered low-tide transect passes to be those occurring when the predicted tidal height in Australian chart datum (height above lowest astronomical tide) fell below the mean value for the study area $(1.40 \mathrm{~m}$, Sargeant et al. 2005); high-tide passes occurred when the predicted tidal height exceeded this threshold. Actual measured depths at low tide averaged $1.32 \mathrm{~m}$, while those at high tide averaged $3.13 \mathrm{~m}$. During each transect pass we recorded all $H$. elegans sighted within $5 \mathrm{~m}$ of the vessel (i.e. within a $10 \mathrm{~m}$ sighting belt) and whether each individual was engaged in foraging or another behavior (resting or traveling). Foragers were defined as individuals actively probing the substrate with their heads or with their heads inserted into the substrate and their tails sticking up into the water column; swimmers were defined as individuals traveling through the water column without showing any interest in or making contact with the substrate, and resting individuals were those lying motionless on the ocean floor. Sea snakes were difficult to detect on cloudy and windy days. Thus, we only conducted transects on days when cloud coverage was $\leq 20 \%$ and Beaufort wind conditions were $\leq 1$.

Tiger shark abundance. The abundance of tiger sharks in the study area fluctuates seasonally (Wirsing et al. 2006). We assayed Hydrophis elegans habitat use during the Austral warm season when local shark numbers typically are high, and this pattern persisted in 2004 (Wirsing et al. 2006). Therefore, the need for sea snakes to invest in anti-predator defense presumably was great during the course of the present study.
Importantly, other sympatric species that are subject to predation by tiger sharks invested heavily in antipredator behavior during the months in which the present investigation took place (e.g. bottlenose dolphins Tursiops aduncus, Heithaus \& Dill 2002; dugongs Dugong dugon, Wirsing et al. 2007a,b).

Statistical analysis. For all snakes and forager-only groups, we typically encountered no more than 1 individual per transect run. Consequently, our dependent variables (snake and forager sighting frequency) were best expressed as a binomial, leading us to model them using logistic regression. For the model of overall Hydrophis elegans abundance, we made habitat type (sand flat versus seagrass), tidal state (high versus low) and the interaction between these 2 factors available for inclusion as predictor variables. In addition, the transect was included as a blocking factor to account for spatial heterogeneity in the observations. For the model of forager abundance, data from transect passes over seagrass habitat were not analyzed, and only tidal state and transect served as predictor variables because foraging was not observed over seagrass in spite of 94 transect passes through this habitat type. Relationships were considered significant at $\alpha=0.05$ for both models.

\section{RESULTS}

We sighted a total of 63 individual Hydrophis elegans, 14 of which were engaged in foraging. Overall, tidal state and the interaction between habitat and tidal state were significant predictors of $H$. elegans abundance (Table 1). Snakes were sighted significantly more frequently in seagrass habitat than in sand flat habitat at high tide, while sighting rates in the 2 habitats did not differ at low tide (Fig. 2). Foraging snakes only were encountered in sand habitats and the probability of sighting a foraging snake differed significantly according to tidal state (Table 2), with this behavior occurring primarily at low tide (12 of 14 cases, Fig. 3).

Table 1. Logistic regression analysis of the influence of habitat (sand flat versus seagrass), tidal state (high versus low), transect (spatial heterogeneity) and the interaction between habitat and tide on the probability of sighting bar-bellied sea snakes Hydrophis elegans along $2 \mathrm{~km}$ transects. Significant values are shown in bold.

\begin{tabular}{|lcccc|}
\hline Variable & $\beta$ & Odds ratio & $t$-ratio & $\mathrm{p}$ \\
\hline Habitat & -0.25 & 0.78 & -0.56 & 0.578 \\
Tide & -1.38 & 0.25 & -2.61 & $\mathbf{0 . 0 0 9}$ \\
Transect & 0.23 & 1.26 & 1.84 & 0.066 \\
Habitat $\times$ Tide & 1.87 & 6.51 & 2.71 & $\mathbf{0 . 0 0 7}$ \\
\hline
\end{tabular}




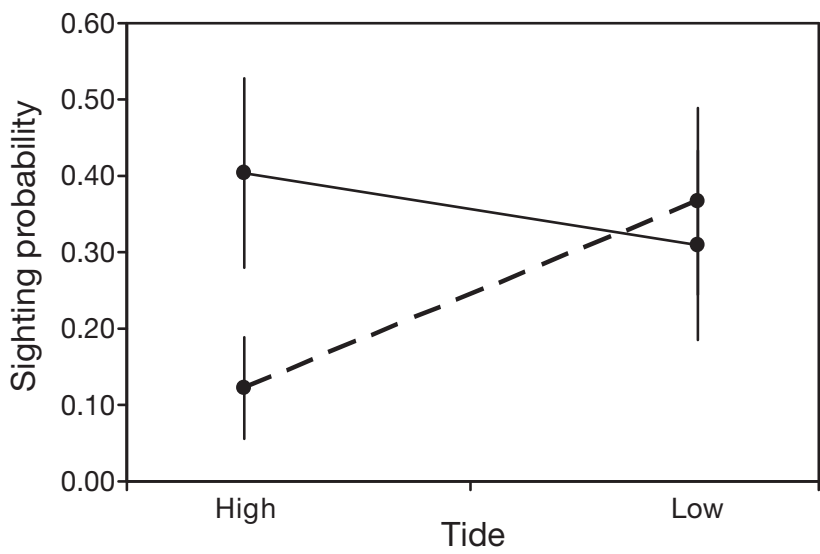

Fig. 2. Hydrophis elegans. Relative abundance, all snakes (estimates of sighting probability $\pm 95 \%$ confidence intervals, transects pooled) in sand flat (dashed line) and seagrass (solid line) habitats at high and low tide

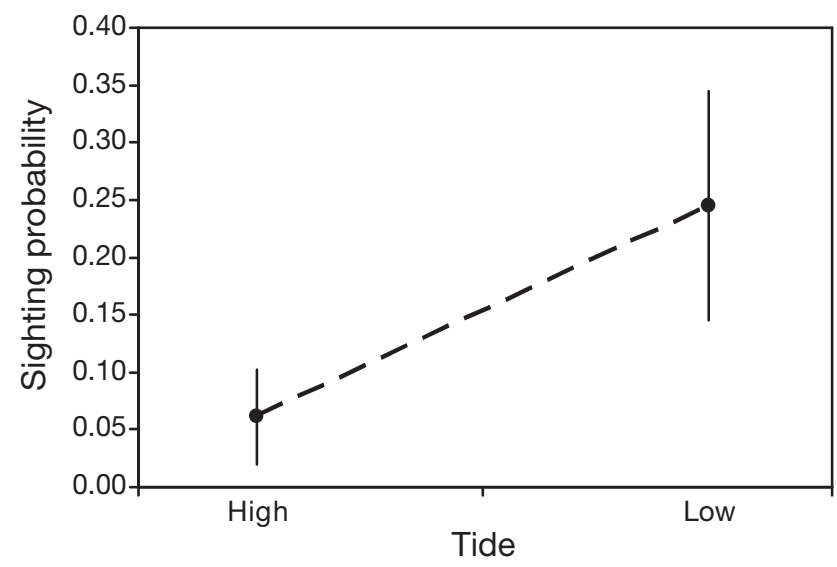

Fig. 3. Hydrophis elegans. Relative abundance, foraging snakes only (estimates of sighting probability $\pm 95 \%$ confidence intervals, transects pooled) in sand flat habitat at high and low tide. No foraging snakes were observed during 94 transect passes through seagrass habitats

\section{DISCUSSION}

Interactions between abiotic conditions and antipredator investment by marine prey species are poorly documented despite the likelihood that they are prevalent. In the present study we showed that the sea snake Hydrophis elegans invests in anti-predator defense only when diurnal abiotic conditions necessitate safety-conscious behavior: in accord with our predictions, $H$. elegans selected seagrass (refuge) habitats over exposed sand flat habitats during high tide when the presence of tiger sharks was elevated, foraged exclusively in sand flat habitats and foraged primarily at low tide when the danger of shark attack was mini-
Table 2. Logistic regression analysis of the influence of tidal state and transect on the probability of sighting foraging Hydrophis elegans. Includes only sightings over sand flats because foraging was not observed over inshore seagrass meadows

\begin{tabular}{|lrcrc|}
\hline Variable & $\beta$ & Odds ratio & $t$-ratio & $\mathrm{p}$ \\
\hline Tide & -1.56 & 0.21 & -2.27 & $\mathbf{0 . 0 2 3}$ \\
Transect & 0.24 & 1.27 & 1.08 & 0.280 \\
\hline
\end{tabular}

mal. These results have important implications for our understanding of sea snake habitat use, the ecological role of large sharks in nearshore marine ecosystems, use of shallow coastal habitats in Shark Bay by tiger sharks and studies of anti-predator behavior that do not consider the possible role of abiotic factors in mediating predator-prey interactions.

Habitat use by sea snakes has been studied rarely (e.g. Burns \& Heatwole 1998). Moreover, no study to date has explored the habitat choices of a sea snake species in the context of predation risk, though Shine et al. (2003) postulated that immature turtle-headed sea snakes Emydocephalus annulatus might use shallow, inshore waters $(<1 \mathrm{~m}$ in depth) as a means to escape shark predation. Our results reveal that the threat of predation can affect sea snake patch use decisions, eliciting the abandonment of otherwise profitable foraging habitats during dangerous time periods. Such sacrifices by sea snakes are likely ubiquitous given that the ranges of many sea snake species overlap with those of sharks for which they are regular prey (e.g. Galeocerdo cuvier and Carcharhinus melanopterus, Lyle \& Timms 1987). Consequently, we suggest that future studies of sea snake habitat use that ignore the potential influence of shark predators may yield erroneous results and that explicit consideration of shark predation danger by such studies should lead to an improved understanding of sea snake ecology.

Our results also reveal that some Hydrophis elegans individuals are willing to use exposed foraging habitat when sharks are present. While foraging primarily occurred at low tide, 2 individuals were sighted foraging over sand at high tide. Though an explanation for this risk-taking behavior will require further analysis, we suggest that it may be the result of depressed condition. That is, individual snakes in poor condition with few assets to protect may be willing to expose themselves to danger in order to exploit food resources during periods when individuals in better condition opt for safety (Clark 1994).

The tight fit between our predictions and the results of this analysis suggests strongly that tiger shark predation risk was responsible for the observed habitat 
shifts by Hydrophis elegans, but other possible explanations do exist. For example, smaller sharks, changes in temperature or reduced snake eel (i.e. food) availability might have induced $H$. elegans to avoid sand flat habitats at high tide. Furthermore, our results could have been an artifact of differences in our ability to detect sea snakes in sand flat and seagrass habitats. We consider these possibilities to be unlikely because (1) the small shark species commonly observed in the present study area (the milk shark Rhizoprionodon acutus and nervous shark Carcharhinus cautus) are not major predators of sea snakes (White et al. 2004), (2) water temperature differences between tidal states were not detected (Kerford 2005), (3) foraging over sand flats at high tide by $H$. elegans was observed both during transect passes and focal animal follows (Kerford 2005), rejecting the explanation that snake eels are only available at low tide, and (4) foraging and traveling $H$. elegans were easy to spot in both habitats under all conditions (Kerford 2005), and the likelihood that we missed sea snakes resting or hiding in seagrass habitats does not confound our results because the visibility of such individuals did not vary with tide (20 sightability trials per tidal state, 5 recumbent sea snake decoys deployed haphazardly along a seagrass transect per trial $t_{38}=-0.16, \mathrm{p}=0.877$ ). Furthermore, if there was marked variation in sighting efficiency in seagrass habitats, more snakes should have been observed in this habitat at low tide; however, the opposite trend was found.

Our conclusions also rest on the assumptions that snake eels are indeed found predominantly in sand flat habitat and that seagrass serves as a protective refuge for sea snakes. We are confident in the first assumption because an intensive survey of both habitats revealed an abundance of burrows in sand flat habitat (mean \pm $\mathrm{SE}=87.6 \pm 15.1$ burrows $\mathrm{m}^{-2}$ ) and no evidence of eel burrowing activity (i.e. presence) in substrate covered by seagrass (ANOVA, $F_{3,84}=5.29, \mathrm{p}=0.002$ ). The second assumption is corroborated by our finding that decoy sea snakes placed within seagrass habitat are highly cryptic and often difficult to retrieve (mean \pm $\mathrm{SE}=1.1 \pm 0.8$ decoys retrieved out of 5 during sightability trials) relative to those over sand habitat $(3.2 \pm$ 0.9 decoys retrieved) $\left(t_{38}=7.90, \mathrm{p}<0.001\right)$ and the fact that our attempts to follow sea snakes in seagrass habitats were often frustrated by snakes moving entirely under the seagrass canopy.

The ecological role of large sharks is hotly debated, largely because few studies have documented interactions between sharks and their prey that might trigger changes in marine community structure (Heithaus 2008). A small but growing body of evidence, however, suggests that large sharks may exert strong top-down effects on marine communities. For example, Myers et al. (2007) argue that the collapse of the bay scallop Argopecten irradians fishery off North Carolina, USA, was the result of a numerical increase in their elasmobranch predators due to a large decrease in shark abundance. Furthermore, in Shark Bay, Western Australia, tiger sharks influence the spatial pattern of herbivory by large grazers (the green sea turtle Chelonia mydas and dugong Dugong dugon) and may therefore indirectly affect seagrass meadow composition and structure (Heithaus et al. 2007, Wirsing et al. 2007a,b). The present study suggests that tiger sharks hinder Hydrophis elegans from exploiting snake eels in nearshore sand flat habitats at high tide and, as a result, provide snake eels with a temporal refuge from predation. By inference, then, any change in the use of inshore habitats by sharks could alter the temporal pattern of predation pressure imposed by $H$. elegans on snake eels in a manner that could induce community restructuring. Studies addressing this possibility should enhance our understanding of the top-down role of large sharks in Shark Bay and other inshore systems where sharks and sea snakes coincide.

The high frequency of occurrence of sea snakes in the stomach contents of tiger sharks in Shark Bay led Heithaus (2001) to suggest that seasonal variation in tiger shark abundance in the bay's Eastern Gulf might be linked in part to the availability of sea snakes. A comparison of sea snake and tiger shark numbers in offshore habitats within the current study area provided no support for this hypothesis (Wirsing et al. 2007c). The results of the present study, however, suggest that such a link could exist in Shark Bay's shallower, nearshore habitats. Indeed, tiger sharks and sea snakes may be engaged in a habitat use game in these areas, with sharks seeking to catch snakes willing to forage at tidal levels above the threshold of safety and snakes seeking to maximize their energetic intake rates without crossing this threshold. A more detailed analysis of individual movements across the tidal gradient for both species will be required to answer this question.

The outcomes of species interactions are often influenced by abiotic factors (Warner et al. 1993, Martin 2001). Consequently, studies of these interactions that fail to consider abiotic conditions may yield incomplete or spurious results. Had the present study not explicitly considered the rise and fall of the tide, for example, we would have completely missed the effect of tiger sharks on the habitat use and foraging behavior of Hydrophis elegans. We conclude, therefore, that an increased focus on interactions between abiotic factors and defensive investment by prey will improve our ability to detect and predict species responses to and the top-down effects of predators across marine systems and taxa. 
Acknowledgements. We thank T. Bujas and N. Maynard for their assistance in the field, D. Charles for logistical support and the use of a research vessel, D. Massey of the Monkey Mia Dolphin Resort for accommodation, B. Sargeant for tidal data and anonymous referees for helpful comments. The present study was conducted under the authority of Western Australia Department of Conservation and Land Management permits SF004410 and CE000532 and Simon Fraser University Animal Care permit \#659B-03. Financial support was provided by NSERC grant A6869 (L.M.D.) and PADI AWARE Australia (grant to M.R.K.). This is contribution number 32 of the Shark Bay Ecosystem Research Project.

\section{LITERATURE CITED}

Burns G, Heatwole H (1998) Home range and habitat use of the olive sea snake Aipysurus laevis on the Great Barrier Reef, Australia. J Herpetol 32:350-358

Clark CW (1994) Anti-predator behavior and the assetprotection principle. Behav Ecol 5:159-170

Culp JM, Glozier NE, Scrimgeour GJ (1991) Reduction of predation risk under the cover of darkness: avoidance response of mayfly larvae to a benthic fish. Oecologia 86:163-169

Gawlik DE (2002) The effects of prey availability on the numerical response of wading birds. Ecol Monogr 72:329-346

Griffin PC, Griffin SC, Waroquiers C, Mills LS (2005) Mortality by moonlight: predation risk and the snowshoe hare. Behav Ecol 16:938-944

Hamilton IM, Heithaus MR (2001) The effects of temporal variation in predation risk on anti-predator behaviour: an empirical test using marine snails. Proc R Soc Lond B Biol Sci 268:2585-2588

Handeland SO, Järvi T, Ferno A, Stefansson SO (1996) Osmotic stress, anti-predator behaviour, and mortality of Atlantic salmon (Salmo salar) smolts. Can J Fish Aquat Sci 53:2673-2680

Hays GC (2003) A review of the adaptive significance and ecosystem consequences of zooplankton diel vertical migrations. Hydrobiologia 503:163-170

Heatwole H (1999) Sea snakes. University of New South Wales Press, Sydney

Heithaus MR (2001) The biology of tiger sharks Galeocerdo cuvier in Shark Bay, Western Australia: sex ratio, size distribution, diet and seasonal changes in catch rates. Environ Biol Fishes 61:25-36

Heithaus MR, Dill LM (2002) Food availability and tiger shark predation risk influence bottlenose dolphin habitat use. Ecology 83:480-491

Heithaus MR, Frid A, Wirsing AJ, Dill LM and others (2007) State-dependent risk-taking by green sea turtles mediates top-down effects of tiger shark intimidation in a marine ecosystem. J Anim Ecol 76:837-844, doi:10.1111/j.13652656.2007.01260.x

Heithaus MR, Frid A, Wirsing AJ, Worm B (2008) Predicting ecological consequences of declines in marine top predators. Trends Ecol Evol 23:202-210

Kerford M (2005) The ecology of the bar-bellied sea snake Hydrophis elegans in Shark Bay, Western Australia. MSc thesis, Simon Fraser University, Burnaby

Lima SL (1998) Non-lethal effects in the ecology of predator-prey interactions. Bioscience 48:25-34

Lima SL, Bednekoff PA (1999) Temporal variation in danger drives anti-predator behaviour: the predation risk allocation hypothesis. Am Nat 153:649-659

Lyle JM, Timms GJ (1987) Predation on aquatic snakes by sharks from northern Australia. Copeia 1987:802-803
Martin TE (2001) Abiotic vs. biotic influences on habitat selection of coexisting species: climate change impacts? Ecology 82:175-188

McCosker JE, Rosenblatt RH (1993) A revision of the snake eel genus Myrichthys (Anguilliformes: Ophichthidae) with the description of a new eastern Pacific species. Proc Calif Acad Sci 48:153-169

Moore MK, Townsend VR Jr (1998) The interaction of temperature, dissolved oxygen and predation pressure in an aquatic predator-prey system. Oikos 81:329-336

Myers RA, Baum JK, Shepherd TD, Powers SP, Peterson CH (2007) Cascading effects of the loss of apex predatory sharks from a coastal ocean. Science 315:1846-1850

> Orth RJ, Heck KL Jr, van Montfrans J (1984) Faunal communities in seagrass beds: a review of the influence of plant structure and prey characteristics on predator-prey relationships. Estuaries 7:339-350

> Ovadia O, Schmitz OJ (2004) Weather variation and trophic interaction strength: sorting the signal from the noise. Oecologia 140:390-406

Sargeant BL, Mann J, Berggren P, Krützen M (2005) Specialization and development of beach hunting, a rare foraging behavior, by wild bottlenose dolphins (Tursiops sp.). Can J Zool 83:1400-1410

Shine R, Shine T, Shine B (2003) Intra-specific habitat partitioning by the sea snake Emydocephalus annulatus (Serpentes, Hydrophiidae): the effects of sex, body size and colour pattern. Biol J Linn Soc 80:1-10

Simpfendorfer C (1992) Biology of tiger sharks (Galeocerdo cuvier) caught by the Queensland shark meshing program off Townsville, Australia. Aust J Mar Freshw Res 43: 33-43

Simpfendorfer CA, Goodreid AB, McAuley RB (2001) Size, sex, and geographic variation in the diet of the tiger shark (Galeocerdo cuvier) in Western Australian waters. Environ Biol Fishes 61:37-46

Sousa WP (1984) The role of disturbance in natural communities. Annu Rev Ecol Syst 15:353-391

Talman SG, Norkko A, Thrush SF, Hewitt JE (2004) Habitat structure and the survival of juvenile scallops Pecten novaezelandiae: comparing predation in habitats with varying complexity. Mar Ecol Prog Ser 269:197-207

- Warner SC, Travis J, Dunson WA (1993) Effect of pH variation on inter-specific competition between two species of hylid tadpoles. Ecology 74:183-194

Weetman D, Atkinson D (2002) Anti-predator reaction norms for life history traits in Daphnia pulex: dependence on temperature and food. Oikos 98:299-307

White WT, Platell ME, Potter IC (2004) Comparisons between the diets of four abundant species of elasmobranchs in a subtropical embayment: implications for resource partitioning. Mar Biol 144:439-448

Wirsing AJ, Heithaus MR, Dill LM (2006) Tiger shark (Galeocerdo) cuvier abundance and growth rates in a subtropical embayment: evidence from seven years of standardized fishing effort. Mar Biol 149:961-968

Wirsing AJ, Heithaus MR, Dill LM (2007a) Living on the edge: dugongs prefer to forage in microhabitats allowing for escape from rather than avoidance of predators. Anim Behav 74:93-101

- Wirsing AJ, Heithaus MR, Dill LM (2007b) Fear factor: do dugongs (Dugong dugon) trade food for safety from tiger sharks (Galeocerdo cuvier)? Oecologia 153:1031-1040

Wirsing AJ, Heithaus MR, Dill LM (2007c) Can measures of prey availability improve our ability to predict the abundance of large marine predators? Oecologia 153:563-568 